\title{
COLOR ENTRENCHMENT IN MIDDLE-SCHOOL ENGLISH SPEAKERS: COGNITIVE SALIENCE INDEX APPLIED TO COLOR LISTING
}

\author{
Jodi L. Sandford
}

\begin{abstract}
This study presents results of two questionnaires posed to English speaking middle-school students to verify the level of color term entrenchment and color prototypes at the age of 12 . The methods included color listing and informant introspection on a color prototype linguistic construction. Listing techniques have long been used to identify basic categories and prototypically relevant linguistic items. In this case Sutrop's Cognitive Salience Index (2001) served to reveal the facilitation of retrieval of concepts in long-term memory thus allowing us to evince the degree of entrenchment and salience of the given color term. Participant introspection in conjunction with conceptual salience analysis (Talmy 2000, 2005) regarding prototypical items (Rosch 1975, 1978, 1983) was also employed to identify what items are actually associated prototypically with colors at this age. The results are compared to adult color listings and prototypes (for both English and Italian speakers). Divergence is significant both in regard to the Cognitive Salience Index and within group judgment of the color prototypes. Further details about the subordinate color term choices and the agreement on prototypes reveal the conventionalized linguistic color associations made by this specific group of north-west American middle-school students.
\end{abstract}

Keywords: basic color terms, cognitive salience index, color listing, color prototypes, entrenchment, salience

\section{INTRODUCTION}

This paper illustrates the results of two questionnaires presented to middleschool children regarding color conceptualization in English. One questionnaire involved color term listing; a method employed to reveal general color term entrenchment. The other questionnaire asked for informant introspection on color prototypes in relation to the six primary basic color terms (BCT's) (Berlin \& Kay 1991; Kay et al. 2009). Color term listing according to the cognitive semantic approach reveals the degree of entrenchment of specific colors. This approach is concerned with investigating the relationship between experience, the conceptual system, and the semantic structure encoded by language. More 
precisely it is involved in understanding the structure of language, as it emerges from knowledge representation, and the conceptualization in language that is reflected in meaning construction (Evans 2007: 26). As Schmid explains, if words of a language represent the conceptualizations that have been fossilized by convention in a speech community, then their "entrenchment" is the strength or "degree to which the formation and activation of a cognitive unit is routinized and automated" (2007: 118). Croft and Cruse (2004) identify "entrenchment" with the attainment of some sort of default status. Moreover, Langacker (2008: 21) specifies that entrenchment, or unit status, pertains to individual speakers' usage, whereas conventionality pertains to a community of speakers. That is to say that the more we use a specific word, the more automatically we will continue to use it and the more it will become cognitively entrenched for both the speaker and the community of speakers.

By using the Cognitive Salience Index (CSI) developed by Sutrop (2001) I was able to identify the most salient color words in the color lists and rank the degree of entrenchment. The rationale behind the CSI is that there is a correlation between entrenchment of terms and their accessibility for a higher number of the participants. The CSI is the result of the equation CSI $=\mathrm{F} /(\mathrm{N}$ $\mathrm{X} \mathrm{MP}$ ), where $\mathrm{F}$ (relative frequency of a term) is divided by ( $\mathrm{N}$ (number of informants) multiplied by MP (the mean position of the term)). In so doing, the terms that tend to be retrieved more quickly (and therefore tend to be listed among the first entries) have a higher MP, which will result in a higher CSI value. The CSI yields a value between 0 and 1 , with greater values corresponding to greater cognitive salience. The cognitive salience index yields comparable results across studies since it does not depend on the length of the individual lists (Sutrop 2001: 267). Numerous researchers have used the Cognitive Salience Index as a successful means of establishing a reliable ranking of items (see, for example, Kuehnast et al. 2014; Sandford 2015; Sutrop 2000, 2001, 2002: Uusküla \& Sutrop 2007; Uusküla 2007, 2008).

A color term is salient if it is readily elicitable, occurs in the idiolects of most speakers, and is used consistently by individuals and with a high degree of consensus among individuals (Hardin \& Maffi 1997: 4). Schmid defines the notion of salience that "may thus denote both a temporary activation state of mental concepts (cognitive salience) and an inherent and consequently more or less permanent property of entities in the real world (ontological salience). [...] As a result, cognitive events related to the processing of ontologically salient entities will occur more frequently and lead to earlier entrenchment of corresponding cognitive units, or concepts. [...] On the other hand deeply entrenched cognitive units are more likely to become cognitively salient than less well entrenched ones" (2007: 120). 
This is how color listing and color term recall may function as an indication of salience, both cognitive and ontological, in that the informants will reveal exactly those words that are used more frequently by themselves and by the linguistic community they are part of. And at the same time these lists reveal, according to their young age, the degree of entrenchment and salience that color words have for this group of young people in a multi ethnical American community.

Listing techniques have long been used to identify basic categories and prototypically relevant linguistic items. See for example the work by Corbett and Davies (1997: 203-205; 1995) and Davies and Corbett (1995, 1994) who used color name listing to evaluate the correlation between frequency and top of the list ranking as the measure of basicness. Listing is used to reveal exactly the facilitation of retrieval of concepts in long-term memory thus allowing us to evince the degree of entrenchment and salience of the given category items.

In the second questionnaire I asked the informants to write down prototypical items, in keeping with Talmy's (2000) indications on introspection as a methodological research tool. I approached this by giving them the expression, or construction", "as [color] as X". Here [color] stands for one of the 6 primary BCT's and X represents the blank that the informants were asked to fill with the first word that came to mind in relation to that color. As Geeraerts claims, "when informants are asked to enumerate the members of a category, typical members are more often named than marginal ones" (2009: 187). These typical members are known as prototypes, or cognitive representations of best exemplars. Categories are based on such shared mental concepts. Moreover, by prototypes I mean "the clearest cases of category membership defined operationally by people's judgments of goodness of membership in the category", in keeping with Rosch (1978: 36).

Rosch subsumed the implications of this type of research in 1973. She affirms that the nature of cognitive representations of semantic categories has direct relevance to two important areas of inquiry. One concerns the structure of categories and concepts and has implications for the way in which concepts may be researched. The other area delves into the nature of mental representations, as proposed in the cognitive commitment of cognitive linguistics (see Lakoff 1990 [1987]). These two areas of investigation, the structure of categories and concepts, and their mental representation, are pertinent to this analysis. Furthermore, the commitment, taken into consideration in this approach, represents a dedication to characterizing general principles that apply to all aspects of human language and how they emerge from a common set of human cognitive abilities, and to providing a characterization of the general principles for language that harmonize with what is known about the mind and brain 
from other disciplines. Rosch emphasizes how our ability to process the frame of color is emblematic of this type of revelation of general principles. A color term reveals not only a linguistic prototypical reference point that corresponds to a visual focal color, but also the associated object or prototypical associate itself.

There is now considerable evidence that color categories are processed by the human mind (learned, remembered, denoted, and evolved in languages) in terms of their internal structure; color categories appear to be represented in cognition not as a set of criterial features with clearcut boundaries but rather in terms of a prototype (the clearest cases, best examples) of the category, surrounded by other colors of decreasing similarity to the prototype and of decreasing degree of membership. (Rosch 1975: 193)

In this study we are referring both to the most entrenched color word/concepts for these 12 year olds, and to the central best example of the focal color itself in terms of the object that gives us the cognitive reference to that visual focal color.

Current research, since Berlin and Kay (1991 [1969]) and Kay et al. (2009), generally considers there to be eleven BCTs in English, that fit into the evolutionary hierarchy of BLACK and WHITE, RED, YELLOW and GREEN, BLUE, GREY and BROWN, PURPLE, PINK, ORANGE (see Biggam 1997; Casson 1997; Dedrick et al. 2005; Sandford 2012). These colors plus one were used as the basis for this analysis.

\section{METHOD}

\section{Informants}

The informants included 29 students, 16 females and 13 males from the Explorer Middle School in Everett, Washington. The class of students was a special group of highly gifted or "honor" students. The average age was 11.6 years old, the oldest 12 and the youngest 11. All of the students were native American English speakers. Observing the ethnic mixture of the students, I asked them if they spoke another language at home and 24 students raised their hands. So it is relevant to note that a majority of these advanced students from this suburban neighbourhood had some sort of bilingual input. Their parents were from over 7 different countries: USA, China, Korea, India, Italy, Central America, and South America. 


\section{Procedure}

The students received a short briefing explaining that we were going to be talking about color, but before discussing the matter, so as not to prime their responses, I wanted them to list color words by writing them down on the piece of paper I had put on their desks. I asked them to fold the paper into three parts horizontally, and write as many color words as they could in each column. I explained that they would have a minute for each column for a total of three minutes and that I would tell them when to move to each column.

After this the students were asked to fill in a separate paper questionnaire. Each questionnaire had 12 phrases listed on the paper, two for each of the six primary BCTs: Black, White, Red, Yellow, Green, Blue. There was a blank next to each phrase "as [color] as X", for example, as black as ............, and the informants were instructed to write the first word that they associated with the color in the blank.

These data were also analyzed using the Cognitive Salience Index (Sutrop 2001) taking into account two important aspects: term frequency and mean position (see above). The cognitive salience index was calculated to find the CSI rank of each color word in the lists of colors provided by the informants.

\section{RESULTS}

The students put together a list of 163 different color names. The total list included 730 items. The longest list included 39 colors and the shortest list 15 colors (SD 7.34). An average of 25 colors total per informant, 14 colors average the first minute, 6 colors average the second minute, and 5 colors average the third minute. Of the 163 different colors, only 16 colors were named by half of the informants, another 17 colors were named by 13 to 6 informants. This means that 130 of the colors were named by fewer than 5 informants ( 4 colors were named by 5 informants, 10 colors by 4,11 colors by 3,18 colors by 2 , and 87 colors by 1 ). Appendix 1 shows the 25 colors with the highest CSI. All of the colors are listed in note $2^{2}$.

\section{Listing task and CSI}

Table 1 shows the top 12 CSI colors: Red, Orange, Yellow, Blue, Green, Purple, Magenta, Black, Pink, White, Brown, and Grey. The CSI is considered the measure of the most prominent/salient colors named by a group of people. 
Table 1. The Twelve Top CSI Colors.

\begin{tabular}{|l|c|c|c|c|c|c|c|}
\hline COLOR & MP & $\begin{array}{c}\text { MP } \\
\text { RANK }\end{array}$ & FREQ & $\begin{array}{c}\text { \% } \\
\text { FREQ }\end{array}$ & $\begin{array}{c}\text { FREQ } \\
\text { RANK }\end{array}$ & $\begin{array}{c}\text { CSI } \\
\text { (S = F / (N X MP) }\end{array}$ & $\begin{array}{c}\text { CSI } \\
\text { RANK }\end{array}$ \\
\hline Red & 4 & 1 & 28 & 97 & 3 & 0.2414 & $\mathbf{1}$ \\
\hline Orange & 5 & 2 & 29 & 100 & 1 & 0.2000 & $\mathbf{2}$ \\
\hline Yellow & 5 & 3 & 28 & 97 & 4 & 0.1931 & $\mathbf{3}$ \\
\hline Blue & 5 & 4 & 27 & 93 & 5 & 0.1862 & $\mathbf{4}$ \\
\hline Green & 5 & 5 & 27 & 93 & 6 & 0.1862 & $\mathbf{5}$ \\
\hline Purple & 8 & 8 & 25 & 86 & 9 & 0.1078 & $\mathbf{6}$ \\
\hline Magenta & 9 & 9 & 27 & 93 & 7 & 0.1034 & $\mathbf{7}$ \\
\hline Black & 11 & 19 & 26 & 90 & 8 & 0.0815 & $\mathbf{8}$ \\
\hline Pink & 13 & 29 & 29 & 100 & 2 & 0.0769 & $\mathbf{9}$ \\
\hline White & 12 & 24 & 25 & 86 & 10 & 0.0718 & $\mathbf{1 0}$ \\
\hline Brown & 14 & 34 & 25 & 86 & 11 & 0.0616 & $\mathbf{1 1}$ \\
\hline Grey & 14 & 35 & 24 & 83 & 12 & 0.0591 & $\mathbf{1 2}$ \\
\hline
\end{tabular}

I calculated the Index for all of the colors and ranked them accordingly. The colors that had the highest Frequency ranks were Orange, Pink, Red, Yellow, Blue, Green, Magenta, Black, Purple, White, Brown, and Grey. The colors Black, White, Brown, and Grey do not change rank between the two measures: frequency and CSI. Orange, Red, and Yellow rank in the top four in both rankings, but the Mean Position ranking changes. Yellow, Blue, and Green stay in the same order for both rankings.

The main shifts in rank are Pink and Purple, and Magenta to a lesser degree. That is, Pink was listed by all of the informants but only later in the lists, Purple was listed by fewer informants but much earlier in the lists. Magenta was the only non-BCT that was listed by almost all the informants fairly early in the lists. This is why Sutrop's Index is so informative; by including all the different aspects of information in the calculation we are able to give a more accurate idea of the individual entrenchment and the group response. 


\section{Prototype listing task}

The two most common objects, or prototypes, that emerged for each color construction list are: Night and Pitch for Black; Paper and Snow for White; Blood and Rose for Red; Sun and Dandelions for Yellow; Grass and Leaves for Green; Sky and Ocean for Blue. Table 2 lists the 4 most frequent associates. In this case I applied the CSI, though the variation in MP is limited since there were only two items per informant. It still became pertinent to see if the prototypes emerged first or second. For example, in the case of Green Emeralds were listed only twice but in both occasions first, and Frogs were listed 3 times but always second, which resulted in a lower CSI.

Table 2. Four Top CSI Color Prototypes per Color for 29 Informants.

\begin{tabular}{|l|l|l|l|l|l|l|l|l|l|l|l|l|}
\hline COLOR & $\begin{array}{l}\text { Prot. } \\
\mathbf{1}\end{array}$ & $\#$ & CSI & $\begin{array}{l}\text { Prot. } \\
\mathbf{2}\end{array}$ & $\#$ & CSI & $\begin{array}{l}\text { Prot. } \\
\mathbf{3}\end{array}$ & $\#$ & CSI & $\begin{array}{l}\text { Prot. } \\
\mathbf{4}\end{array}$ & $\#$ & CSI \\
\hline BLACK & Night & 17 & 0.5205 & Pitch & 6 & 0.1379 & Space & 5 & 0.1232 & Coal & 4 & 0.0788 \\
\hline WHITE & Paper & 19 & 0.4614 & Snow & 9 & 0.2333 & Cloud(s) & 7 & 0.1412 & Light & 3 & 0.0788 \\
\hline RED & Blood & 17 & 0.5010 & Rose(s) & 8 & 0.1692 & Fire & 6 & 0.1379 & Apple & 5 & 0.0958 \\
\hline YELLOW & Sun & 18 & 0.5592 & $\begin{array}{l}\text { Dande- } \\
\text { lions }\end{array}$ & 4 & 0.1103 & Lemons & 4 & 0.0920 & $\begin{array}{l}\text { Ba- } \\
\text { nana }\end{array}$ & 4 & 0.0788 \\
\hline GREEN & Grass & 20 & 0.6270 & Leaves & 9 & 0.1744 & Emeralds & 2 & 0.0690 & Frogs & 3 & 0.0619 \\
\hline BLUE & Sky & 19 & 0.5000 & Ocean & 14 & 0.3376 & Sea & 5 & 0.1232 & Water & 4 & 0.0690 \\
\hline
\end{tabular}

\section{DISCUSSION}

It is pertinent and in keeping with basic color theory that the 11 basic color terms in English [Black, White, Red, Green, Yellow, Blue, Brown, Grey, Purple, Orange, Pink] are most prominent for the 12 year olds. Magenta, rank 7 th in CSI, is the odd one in the list. It is clearly prominent for the middle-school students. An explanation may be tied to the use of computers and the division between the RGB (red, green, blue) autoluminant system that is contrasted to the CYM (cyan, yellow, magenta) pigment system. Cyan was also listed, but only rank 36th in CSI. It may, on the other hand, have to do with their studies. The class was studying the middle ages and there may have been some mention of the pigments that were commonly used at that time. This came to mind since they also listed Indigo, rank 13th CSI. In this case it would suggest that Magenta may be shifting towards a BCT, taking the position that was previously held by 
Pink. As Desgrippes states, "the cognitive representation of a color is dynamic: it can evolve with diachronic language variation or with language shift, and both older and newer representations remain retrievable depending on the task at hand" (2013). This may be the case for the middle-school students who have been exposed to advanced color terminology and in this circumstance, being highly habituated to recall of vocabulary, able to access numerous sophisticated terms especially those that fit the scholastic context.

It is further relevant to see that, after the 12 most prominent colors (Table 1), of the following 12 colors of the list of the 25 highest CSI measure (Appendix 1) 6 colors are types of blue, 3 are types of purple, the other 3 are non-colors, or low in saturation, Gold, Silver, and Tan. Moreover, the high CSI of the BCTs positioned the warm colors Red, Orange, and Yellow first over the cool colors Blue, Green, and Purple. These aspects would appear to be indicative of the initial perceptive salience of warm colors for the 12 year olds on one hand, and on the other to reveal the salience of a significant variation in blue color terms.

Of the total list of 163 colors it is possible to group them according to the form and content. Each group is presented in alphabetical order. Firstly, there are 6 questionable color names: Clear, Neon indigo, Neon black, Neon brown, Rainbow, and UV colors. Of the subordinate (non-basic) color names, there are 9 pigment names: Chinese white, Indigo, Lamp black, Prussian Blue, Rose Madder, Russet, Siena, Ultramarine, Umber; 8 food names: Burgundy, Caramel, Chartreuse, Cream, Raspberry, Peach, Salmon, Strawberry; 7 materials used for jewellery: Amber, Aquamarine, Coral, Ebony, Emerald, Jade, Turquoise; 5 metal names: Bronze, Iron, Gold, Rust, Silver; 5 flowers: Fuchsia, Lavender, Lilac, Periwinkle, Rose; 2 trees/wood: Hazel, Mahogany; 2 materials: Brick, Earth; and 4 other: Egg shell, Jeans, Smokey, Sunset.

Then there is a group of compound color terms, of which only 1 "Bright" color, 1 "Deep" color, 4 "Pastel" colors, 7 "Neon" colors, 9 "Dark" colors, and 11 "Light" colors. They are: 17 Blues (Baby blue, Dark blue, Green-blue, Electric blue, Light blue, Midnight blue, Navy blue, Neon blue, Non-photo blue, Ocean blue, Pastel blue, Powder blue, Robin egg blue, Royal blue, Sea blue, Sky blue, Vibrant blue); 16 Greens (Dark green, Blue green, Faded green, Foam-green, Forest green, Grass green, Hunter green, Light green, Lime green, Mint green, Neon green, Pastel green, Pea green, Yellowish green, Yellow green, Sea green); 13 Yellows (Bright yellow, Bumblebee yellow, Butter yellow, Dark yellow, Fluorescent yellow, Indian yellow, Lemon yellow, Light yellow, Mustard yellow, Neon yellow, Orange yellow, Pastel yellow, Sunshine yellow, and 2 variations Rose-gold and Golden); 10 Pinks (Carnation pink, Coral pink, Electric pink, Hot-pink, Light pink, Neon pink, Pastel pink, Salmon pink, Soft pink, Tickle-me-pink); 7 Reds (Blood red, Dark red, Light red, Neon red, Orange-red, Peach red, Violet red); 
7 Purples (Dark purple, Dark violet, Light purple, Light violet, Neon purple, Red violet, Royal violet); 7 Oranges (Yellow orange, Dark orange, Deep orange, Light orange, Neon orange, Red orange, Sunset orange); 6 Greys (Blue grey, Cool grey, Dark grey, French grey, Gravel Grey, Light grey); 3 Browns (Chocolate brown, Light brown, Reddish-brown); 2 Indigos (Dark indigo, Light indigo); and 1 White (Off-white). The remaining 13 subordinate monolexemic color terms included: Aqua, Azure, Beige, Cerulean, Crimson, Cyan, Magenta, Maroon, Navy, Scarlet, Tan, Teal, Violet (6 blues, 4 reds, 2 browns, and 1 purple). This leaves the remaining 11 BCTs: Black, Blue, Green, Grey, Brown, Orange, Pink, Purple, Red, Yellow, White.

The students demonstrated a large vocabulary that reflected crayon and paint names. Some of the students were also aware of how to compound color words by using adjectives, like neon-yellow, pastel-yellow, light-yellow, darkyellow, or bright yellow, or the colors themselves, for example, orange yellow or yellow orange. So the students used both long-term memory of stable references, objects with color names written on them, and linguistic mechanisms to be able to list as many names as they could.

Generally speaking, the age range considered for the onset of color term establishment reliability acquired of the first focal colors by 3 years and brown and grey 6-9 months later (Pitchford \& Mullen 2002), around 4 years, Moreover, Pitchford and Mullen revealed that "of the 11 basic colors, brown and grey were the two least preferred colors, suggesting a developmental link between color preference and color term acquisition" (Pitchford 2006: 330). It is relevant to note that by 12 these children responses not only rank Brown and Grey lowest, reflecting the same type of preference; they also have a fully developed color term vocabulary.

When I compared these CSI ranking results to color name listings put together from a small group of middle aged American adults who attended a color workshop and a large group of Italian University students (for corresponding CSI see Appendix 1); fundamentally the eleven basic color terms emerged constantly at the top of the rank. The order varies and implies a different level of cognitive salience especially between the English children and the adults. Table 3 shows the first 12 plus 3 rankings with the SD of the ranking that resulted according to the CSI. In order to make the lists comparative I used a Fuchsia for English adults, and Fucsia for Italian adults as a close perceptive equivalent of Magenta that the English middle-school students listed 7th CSI rank. I deemed this to be legitimate since Fuchsia is defined as "magenta in color" in http://www.word reference.com/enit/fuchsia. However, the middleschool kids also named Fuchsia separately, CSI rank 23 on the list, though the adults did not mention Magenta (see Appendix 1). Tan for English students 
and adults and was compared with Beige for Italian adults. The 3 rankings in Table 3 are listed according to the SD, from the lowest to the highest. This is to better illustrate the similarities that emerge.

The two English groups have the same CSI rank only for Purple. The two Adult groups have the same CSI rank for Pink and Green. The Middle school students and the Italian university students have the same CSI rank for Red, Blue, Grey, and Brown. It is hard to say how the specific color position in the list tells us something more specific. The order of approximate cognitive entrenchment results ranking across the three groups again according to SD as: Red, Pink, Green, Purple, Blue, Black, Orange, White, Grey, Yellow, and Brown. The ranking would seem to have positivity bias to it, where the top colors are associated more with positive metonymies and metaphors the higher on the list (see Sandford 2012, forthcoming).

Table 3. General color ranking by CSI results for top 12 color listing (plus 3) and SD rank.

\begin{tabular}{|l|c|c|c|c|}
\hline Color & $\begin{array}{c}\text { English } \\
\text { Middle } \\
\text { school }\end{array}$ & $\begin{array}{c}\text { English } \\
\text { Adults }\end{array}$ & $\begin{array}{c}\text { Italian } \\
\text { Adults }\end{array}$ & SD \\
\hline red & 1 & 2 & 1 & 0.58 \\
\hline pink & 9 & 10 & 10 & 0.58 \\
\hline green & 5 & 3 & 3 & 1.15 \\
\hline purple & 6 & 6 & 8 & 1.15 \\
\hline blue & 4 & 1 & 4 & 1.73 \\
\hline black & 8 & 9 & 5 & 2.08 \\
\hline orange & 2 & 5 & 7 & 2.52 \\
\hline white & 10 & 11 & 6 & 2.65 \\
\hline grey & 12 & 7 & 12 & 2.89 \\
\hline yellow & 3 & 8 & 2 & 3.21 \\
\hline brown & 11 & $\mathbf{1 9}$ & 11 & 4.62 \\
\hline magenta & $\mathbf{7}$ & 21 & 15 & 7.02 \\
\hline other colors named by all three groups & & \\
\hline tan & 20 & 14 & 17 & 3.00 \\
\hline gold & 16 & 23 & 18 & 3.61 \\
\hline turquoise & 15 & $\mathbf{4}$ & $\mathbf{9}$ & 5.51 \\
\hline
\end{tabular}


The color prototypes also seem to be well established, although after the first one exemplar the agreement, revealed through frequency, dropped from 18.6 to 8.3, then to 4.8. The students were creative in their responses, for example, as black as the shirt I am wearing; as white as a rabbit in a snowstorm; as red as the stripes on the American flag; as yellow as the National Geographic magazine; as green as the text on my shirt; as blue as the pencil I am writing with. There were 26 different ideas for Black; 22 for White; 20 for Red; 24 for Yellow; 20 for Green; 17 for Blue (see Appendix 2). The result of Fire only in third place for Red is unusual and would seem to reflect the lack of fire in contemporary suburban life; the same way Sheep is low on the list for White. But 44 of the 58 items listed for Red involved fire, blood, flowers, and fruit. 44 of the Blue items listed involve water of some sort. 40 of the 58 items listed for Green involve grass or leaf vegetation. 38 of the 58 items for Black involve darkness, pitch, and charcoal; and for White involve paper, light, and snow. 37 of the 58 items listed for Yellow involve the sun, flowers, or fruit. This confirms the expectation that the salient features of the natural environment influence the entrenchment of color terms and prototypes.

If we compare these results with a corpus-based analysis by accessing the Corpus of Contemporary American English (COCA); which includes over 520 million words that have been compiled from spoken and written texts dating from 1990 to 2015, all of the principle items listed by the students in the prototype construction are found. "As black as" is found 188 times, with Night as the most frequent collocate, the same as the 12 year olds. "As white as" is found 278 times, with Snow as the most frequent collocate (18) rather than Paper. In COCA Ghost and Chalk emerge with White, which were not mentioned by this group of students. "As red as" is found 152 times, with the agreement of Blood as the most prototypical item. "As yellow as" is found on 23 times and results with Sun as the most frequent prototype too. "As green as" is found 87 times, "as blue as" 95 times with Grass and Sky as the principle prototypes in agreement again with the middle-school students. The Sea and Mediterranean are more frequent than Ocean and Pacific, which instead are more salient and entrenched for the Washingtonians who live right off the Pacific Ocean. COCA show Robin's egg as frequently associated with Blue, which was not mentioned by the students.

\section{CONCLUSION}

The aim of this paper has been to add an account of young English speaking middle-school students input to color listing and color prototype analysis. The two questionnaires about color terms and prototypes respond well to theories 
of language processing and the prototypical color constructions. Overall, the results have shown (i) that 12 year olds in a suburban multi-ethnical society already have a well entrenched color vocabulary; (ii) at this age students are already able to use linguistic devices, such as compounding to augment the vocabulary they have at disposition; (iii) the CSI allows us to untangle the multifaceted responses arriving at an accurate picture of what terms are actually entrenched and salient for the specific group; and (iv) the construction "as [color] as x" allows the students to access the prototypes that prove to be equivalent in convention to large corpus analyses. This study should serve as a base to characterize color listing and construction queries as a strong predictor of linguistic entrenchment and salience of a specific linguistic frame in language acquisition. The theoretical claim is that the basic principles of frequency and mean position in relation to number of participants allow us to establish a relevant ranking that can be compared to other linguistic groups.

As Orians (forthcoming) states many universal human traits, such as classification of basic colors, have probably evolved in response to those stable parts of the environment. Specific behavior would be impossible in the absence of "neural filters that emphasize or de-emphasize components of aspects of information" (Marler 1961). Hence, this group of young informants is already totally aware and capable of filtering, categorizing, and selecting the responses to this type of linguistic inquiry according to their interaction with the environment. The prototypes and color terms result to be totally entrenched at this age. The theoretical base of this study stems from what Schmid calls the 'Entrenchment-andConventionalization Model' (cf. Schmid 2013: 106-107, 2014: 242-254; Schmid 2015; Schmid \& Mantlik 2015) ${ }^{3}$. Thus the cognitive processes employed by this study's informants may be "subsumed" under the label entrenchment, whereas the social processes or agreement taking place in this speech community may be identified under the label of conventionalization. Schmid's model predicts that the interaction of various components makes linguistic structure emerge and be perpetuated. Linguistic entrenchment may be considered according to the salience of specific usage that evolves through use and exposure, through instruction and the development of general cognitive abilities. It is likely that this group of mostly bilingual middle-school students have a particularly high level ability to process, memorize, categorize, and respond this type of task. As Ibbotson and Tomasello specify "the problem for language acquisition is that children do not experience constructions but only utterances; they must (re-)construct for themselves the constructions of their language from the individual utterances they experience" (2009: 60); hence, more exposure, more language, more elaborate usage, greater development. It will be interesting to see if these results, degree of salience, entrenchment, and conventionalization, can be replicated for people of this age, both in other English speaking groups and in other languages. 


\section{APPENDIX 1}

The 24 highest ranking colors by Cognitive Salience Index $(\mathbf{S}=\mathbf{F} /(\mathbf{N} \times \mathbf{M P})$

\begin{tabular}{|c|c|c|c|c|c|c|c|c|}
\hline \multicolumn{5}{|c|}{$\begin{array}{l}\text { Middle School English - } \\
\text { mean age } 12 \\
163 \text { colors total }\end{array}$} & \multicolumn{2}{|c|}{$\begin{array}{l}\text { Adults English - } \\
\text { mean age } 52 \\
126 \text { colors total }\end{array}$} & \multicolumn{2}{|l|}{$\begin{array}{l}\text { Adults Italian - } \\
\text { mean age } 22 \\
134 \text { colors total }\end{array}$} \\
\hline COLOR & MP & FREQ & CSI & $\begin{array}{c}\text { CSI } \\
\text { RANK }\end{array}$ & COLOR & CSI & COLOR & CSI \\
\hline Red & 4 & 28 & 0.2414 & 1 & Blue & 0.1922 & rosso $($ red $)$ & 0.2612 \\
\hline Orange & 5 & 29 & 0.2000 & 2 & Red & 0.1546 & giallo (yellow) & 0.2029 \\
\hline Yellow & 5 & 28 & 0.1931 & 3 & Green & 0.0851 & verde (green) & 0.1731 \\
\hline Blue & 5 & 27 & 0.1862 & 4 & Turquoise & 0.0712 & blu (blue) & 0.1531 \\
\hline Green & 5 & 27 & 0.1862 & 5 & Orange & 0.0658 & nero (black) & 0.1248 \\
\hline Purple & 8 & 25 & 0.1078 & 6 & Purple & 0.0634 & bianco (white) & 0.1189 \\
\hline Magenta & 9 & 27 & 0.1034 & 7 & Grey & 0.0625 & $\begin{array}{l}\text { arancione } \\
\text { (orange) }\end{array}$ & 0.1052 \\
\hline Black & 11 & 26 & 0.0815 & 8 & Yellow & 0.0575 & viola (purple) & 0.0977 \\
\hline Pink & 13 & 29 & 0.0769 & 9 & Black & 0.0512 & $\begin{array}{l}\text { azzurro } \\
\text { (turquoise) }\end{array}$ & 0.0866 \\
\hline White & 12 & 25 & 0.0718 & 10 & Pink & 0.0494 & rosa (pink) & 0.0860 \\
\hline Brown & 14 & 25 & 0.0616 & 11 & White & 0.0488 & $\begin{array}{l}\text { marrone } \\
\text { (brown) }\end{array}$ & 0.0827 \\
\hline Grey & 14 & 24 & 0.0591 & 12 & Teal & 0.0413 & grigio (grey) & 0.0787 \\
\hline Indigo & 9 & 15 & 0.0575 & 13 & $\begin{array}{l}\text { Lime } \\
\text { green }\end{array}$ & 0.0392 & $\begin{array}{l}\text { celeste (light } \\
\text { blue) }\end{array}$ & 0.0637 \\
\hline Violet & 12 & 19 & 0.0546 & 14 & Tan & 0.0342 & lillà (lavender) & 0.0391 \\
\hline Turquoise & 10 & 13 & 0.0448 & 15 & Lavender & 0.0335 & fucsia (fuschia) & 0.0377 \\
\hline Gold & 15 & 14 & 0.0322 & 16 & Burgundy & 0.0316 & indaco (indigo) & 0.0344 \\
\hline Silver & 17 & 15 & 0.0304 & 17 & Aqua & 0.0300 & beige (beige) & 0.0304 \\
\hline Teal & 13 & 9 & 0.0239 & 18 & Mustard & 0.0291 & oro (gold) & 0.0290 \\
\hline Navy blue & 13 & 8 & 0.0212 & 19 & Brown & 0.0257 & porpora (violet?) & 0.0225 \\
\hline Tan & 15 & 9 & 0.0207 & 20 & Beige & 0.0244 & $\begin{array}{l}\text { rosso bordeaux } \\
\text { (burgundy) }\end{array}$ & 0.0217 \\
\hline Light blue & 14 & 8 & 0.0197 & 21 & Fuchsia & 0.0236 & argento (silver) & 0.0199 \\
\hline Dark blue & 15 & 8 & 0.0184 & 22 & \begin{tabular}{|l|}
$\begin{array}{l}\text { Forest } \\
\text { green }\end{array}$ \\
\end{tabular} & 0.0214 & $\begin{array}{l}\text { giallo ocra } \\
\text { (mustard) }\end{array}$ & 0.0194 \\
\hline Fuchsia & 14 & 7 & 0.0172 & 23 & Gold & 0.0171 & $\begin{array}{l}\text { verde acqua } \\
\text { (aqua) }\end{array}$ & 0.0183 \\
\hline Lavender & 15 & 7 & 0.0161 & 24 & Chartreuse & 0.0254 & $\begin{array}{l}\text { cremisi } \\
\text { (carmine) }\end{array}$ & 0.0154 \\
\hline
\end{tabular}




\section{APPENDIX 2}

The two responses to each color construction (as [color] as $\mathrm{x}$ ) listed in the order of frequency. The 26 different ideas for Black were Night, Pitch, Space, Coal, A screen, Dark, Cats, Charcoal, Ebony, A heart, A hole, Horses, Jet, Lead, My eyes, Pavement, Pupil, A raven, Shadow, Slate, Snow-White's hair, Soot, Tar, The shirt I'm wearing, This print, Witch's cat. The 22 ideas for White were Paper, Snow, Cloud(s), Light, (no answer), The sun, A birch tree, Blinding light, The ceiling light, A dove, Egg-whites, Lightning, My socks, A rabbit in snow storm, Sand, A sheep, The moon, The pants I'm wearing, The sclera of the eye, Tissues, A wedding gown, The walls. The 20 ideas for Red were Blood, Rose(s), Fire, An apple, Cherries, A heart, Raspberries, (nothing), The lines on the American Flag, The first color in rainbow, A Ferrari, A fire engine, An Italian Flag, Lipstick, Mars, My ear buds, Rust, A stop sign, Sun-ish, Tomatoes. The 24 ideas for Yellow were The sun, A banana, Dandelions, Lemons, (nothing), Daffodils, A canary, The stars, Butter, Cartoon-stars, Corn, Egg-yolk, A field of flowers, Fire, Flowers, Gold, A bumblebee, A light bulb, The National Geographic magazine, Part of a flame, A school-bus, Sunflower, Sunshine, Trees in the fall. The 20 ideas for Green were Grass, Leaves, Trees, A Forest, Frogs, (nothing), A lime, Emeralds, Wild Grass, The text on my shirt, Over brush in a tree, A plant, A pine tree, A high-lighter, Granny apples, A field, Ferns, Broccoli, Barf, Asparagus, A field. The 17 ideas for Blue were The sky, The ocean, The sea, Water, Jeans, A whale, (nothing), A blueberry, A car, Eyes, Ice, My eyes, Painters tape, A pool, The pencil I'm writing with, The top left corner of the US Flag, US coast guard uniforms.

\section{ACKNOWLEDGEMENTS}

I would like to thank the students at the Explorer Middle School in Everett, Washington, who kindly cooperated on this study. My special thanks go to their teacher Mary Fitzmaurice, who encourages enthusiasm to learn, creativity, and curiosity. 


\section{NOTES}

1 Construction in cognitive linguistics refers to the "chunk" of information that is stored in long-term memory in a form function couple. Ibbotson and Tomasello explain, "One of the great theoretical advances in modern linguistics is the recognition that grammatical constructions are conventionalized pairing of complex forms with complex semantic/pragmatic functions. Phrasal patterns and the rules of syntactic combination not only have meaning but also have the capacity to change the meanings of the words they govern" (2009: 59-60). In this study I used the construction "as [color] as $\mathrm{X}$ " as a structure to uncover the prototypes that are associated with the six BCTs in English. I retrieved expressions like "as black as coal", "as white as snow", "as red as blood", where the informants filled the construction gap with the object. (Cf. Construction Grammar, see Goldberg 1995.)

2 The 163 colors named in order of the Cognitive Salience Index: Red, Orange, Yellow, Blue, Green, Purple, Magenta, Black, Pink, White, Brown, Grey, Indigo, Violet, Turquoise, Gold, Silver, Teal, Navy blue, Tan, Light blue, Dark blue, Fuchsia, Lavender, Sky blue, Neon green, Dark green, Yellow green, Crimson, Peach, Aqua, Hot-pink, Neon yellow, Baby blue, Beige, Cyan, Cerulean, Mahogany, Neon pink, Light green, Aquamarine, Scarlet, Siena, Yellow orange, Forest green, Light pink, Umber, Lime green, Blue green, Navy, Electric blue, Neon blue, Maroon, Rose, Salmon pink, Dark purple, Dark red, Chartreuse, Light red, Bronze, Dark orange, UV colors, Neon orange, Dark grey, Burgundy, Light orange, Light yellow, Off-white, Light grey, Jade, Powder blue, Rose-gold, Rust, Ultramarine, Ebony, Red orange, Cream, Periwinkle, French grey, Ocean blue, Emerald, Salmon, Cool grey, Fluorescent yellow, Lilac, Rainbow, Azure, Jeans, Royal blue, Carnation pink, Faded green, Hunter green, Indian yellow, Carmel, Orange-red, Russet, Sea green, Brick, Hazel, Royal violet, Smokey, Sunset, Neon purple, Blood red, Mustard yellow, Prussian blue, Butter yellow, Coral pink, Non-photo blue, Clear, Deep orange, Midnight blue, Rose madder, Sunset orange, Lamp black, Reddish-brown, Robin egg blue, Chinese white, Earth, Electric pink, Golden, Lemon yellow, Light indigo, Light purple, Sunshine yellow, Blue grey, Grass green, Light violet, Pastel pink, Strawberry, Yellowish green, Amber, Pastel yellow, Pea green, Neon red, Pastel blue, Pastel green, Raspberry, Mint green, Chocolate brown, Coral, Vibrant blue, Dark yellow, Bumblebee yellow, Iron, Light brown, Bright yellow, Dark indigo, Egg shell, Neon indigo, Soft pink, Orange yellow, Tickle-me-pink, Dark violet, Peach red, Gravel Grey, Neon brown, Red violet, Neon black, Violet red, Sea blue, Green-blue, Foam-green.

3 The major elements of the model are summarized in four types of activities invariably involved in it-sensory, motor, cognitive, and social activities that constitute the core of the model, thus marking the framework as belonging to the group of usage-based models. Its key assumption is that what we generally assume to be 'language' or 'the linguistic system' comes about and is continuously updated by the interaction of two types of processes: a limited set of cognitive processes operating in the minds of speakers, subsumed under the label 'entrenchment', and a limited set of socio-pragmatic processes operating in communities, subsumed under the label 'conventionalization'. There are three entrenchment processes - association, routinization, and schematization - and four conventionalization processes - innovation, co-adaptation, diffusion, and normation. The interaction of entrenchment and conventionalization processes depends on usage and on the activities involved in usage, and it is influenced by a (probably open-ended) set of cognitive, emotive-affective, pragmatic, and social forces (Schmid \& Mantlik 2015: 587). 


\section{REFERENCES}

Berlin, Brent \& Kay, Paul 1991 [1969]. Basic Color Terms: Their Universality and Evolution. Berkeley \& Los Angeles \& Oxford: University of California Press.

Biggam, Carole P. 1997. Blue in Old English: An Interdisciplinary Semantic Study. Amsterdam \& Atlanta: Rodopi.

Casson, Ronald W. 1997. Color Shift: Evolution of English Color Terms from Brightness to Hue. In: C. L. Hardin \& Luisa Maffi (eds.) Color Categories in Thought and Language. Cambridge: Cambridge University Press, pp. 224-239. http://dx.doi. org/10.1017/cbo9780511519819.010.

Corbett, Greville G. \& Davies, Ian R. L. 1995. Linguistic and Behavioral Measures for Ranking Basic Colour Terms. Studies in Language, Vol. 19, No. 2, pp. 301-357. DOI: $10.1075 / \mathrm{sl} .19 .2 .02 \mathrm{cor}$.

Corbett, Greville G. \& Davies, Ian R. 1997. Establishing Basic Color Terms. In: C. L. Hardin \& Luisa Maffi (eds.) Color Categories in Thought and Language. Cambridge: Cambridge University Press, pp. 197-223. http://dx.doi.org/10.1017/ cbo9780511519819.009.

Croft, William \& Cruse, D. Alan 2004. Cognitive Linguistics. Cambridge: Cambridge University Press. http://dx.doi.org/10.1017/CBO9780511803864.

COCA = Corpus of Contemporary American English . Available at http://corpus.byu.edu/ coca/, last accessed on May 24, 2016.

Davies, Ian R. L. \& Corbett, Greville G. 1994. The Basic Color Terms of Russian. Linguistics, Vol. 32, No. 1, pp. 65-89. http://dx.doi.org/10.1515/ling.1994.32.1.65.

Davies, Ian R. L. \& Corbett, Greville G. 1995. A Practical Field Method for Identifying Probable Basic Colour Terms. Languages of the World, Vol. 9, No. 1, pp. 25-36. Available at http://epubs.surrey.ac.uk/2090/, last accessed on May 24, 2016.

Dedrick, Don \& Sayim, Bilge \& Jameson, Kimberly A. \& Alvarado, Nancy \& Szeszel, Monika K. 2005. Color, Color Terms, Categorization, Cognition, Culture: An Afterword. Journal of Cognition and Culture, Vol. 5, No. 3, pp. 487-495. http:// dx.doi.org/10.1163/156853705774648545.

Desgrippes, Magalie 2013. Dynamic Cognition: When the Best Example Falls Out the Boundary. Colour Language and Colour Categorization Conference, 4-7 June, Institute of the Estonian Language. Tallinn: Eesti Keele Sihtasutus.

Evans, Vyvyan 2007. A Glossary of Cognitive Linguistics. Edinburgh: Edinburgh University Press. Available at http://www.vyvevans.net/GLOSSARY.pdf, last accessed on May 24, 2016.

Geeraerts, Dirk. 2009. Cognitive Semantics. In: Theories of Lexical Semantics. Oxford: Oxford University Press, pp. 182-266. DOI:10.1093/acprof:oso/9780198700302.001.0001.

Goldberg, Adele E. 1995. Constructions: A Construction Grammar Approach to Argument Structure. Chicago \& London: University of Chicago Press.

Hardin, C. L. \& Maffi, Luisa (eds.) 1997. Introduction. In: C. L. Hardin \& Luisa Maffi (eds.) Colour Categories in Thought and Language. Cambridge: Cambridge University Press, pp. 1-18. http://dx.doi.org/10.1017/cbo9780511519819.001.

Ibbotson, Paul \& Tomasello, Michael 2009. Prototype Constructions in Early Language Acquisition. Language and Cognition, Vol. 1, No. 1, pp. 59-85. http://dx.doi. org/10.1515/LANGCOG.2009.004. 
Kay, Paul \& Berlin, Brent \& Maffi, Luisa \& Merrifield, William R. \& Cook, Richard S. 2009. The World Color Survey. Stanford: CSLI.

Kuehnast, Milena \& Wagner, Valentin \& Wassiliwizky, Eugen \& Jacobsen, Thomas \& Menninghaus, Winfried 2014. Being Moved: Linguistic Representation and Conceptual Structure. Frontiers in Psychology, Vol. 5: 1242. http://dx.doi. org/10.3389/fpsyg.2014.01242.

Lakoff, George 1990 [1987]. Women, Fire, and Dangerous Things: What Categories Reveal about the Mind. Chicago \& London: The University of Chicago Press.

Langacker, Ronald W. 2008. Cognitive Grammar: A Basic Introduction. Oxford \& New York: Oxford University Press. doi:10.1093/acprof:oso/9780195331967.001.0001.

Marler, Peter 1961. The Logical Analysis of Animal Communication. Journal of Theoretical Biology, Vol. 1, No. 3, pp. 295-317. http://dx.doi.org/10.1016/00225193(61)90032-7.

Orians, Gordon H. forthcoming. Our Biological Past in Our Modern Verbal World. In: Annalisa Baicchi \& Remì Digonnet \& Jodi L. Sandford (eds.) Epistemology, Embodiment, and Language: Sensory Perceptions and Representations. Studies in Applied Philosophy, Epistemology and Rational Ethics, Berlin: Springer.

Pitchford, Nicola J. 2006. Reflections on How Color Term Acquisition is Constrained. Journal of Experimental Child Psychology, Vol. 94, No. 4, pp. 328-333. http:// dx.doi.org/10.1016/j.jecp.2006.02.004.

Pitchford, Nicola J. \& Kathy T. Mullen, 2002. Is the Acquisition of Basic-Color Terms in Young Children Constrained? Perception, Vol. 31, No. 11, pp. 1349-1370. DOI:10.1068/p3405.

Rosch, Eleanor 1975. Cognitive Representations of Semantic Categories. Journal of Experimental Psychology: General, Vol. 104, No. 3, pp. 192-233. http://dx.doi. org/10.1037/0096-3445.104.3.192.

Rosch, Eleanor 1978. Principles of Categorization. In: Eleanor Rosch \& Barbara B. Lloyd (eds.) Cognition and Categorization. Hillsdale, N.J.: Laurence Erlbaum Associates, pp. 27-48. Available at http://commonweb.unifr.ch/artsdean/pub/gestens/f/as/ files/4610/9778_083247.pdf, last accessed on May 25, 2016.

Rosch, Eleanor 1983. Prototype Classification and Logical Classification: The Two Systems. In: Ellin Kofsky Scholnick (ed.) New Trends in Conceptual Representation: Challenges to Piaget's Theory? Hillsdale, NJ: Lawrence Erlbaum Associates, pp. $73-86$.

Sandford, Jodi L. 2012. Red Clover. Linguaggio e percezione dei colori: uno studio cognitivo applicato all' inglese. Roma: ARACNE editrice S.r.l.

Sandford, Jodi L. 2015. A Cognitive Linguistic Usage Perspective: What is Italian Blu, azzurro, celeste? Do English agree on BLUE semantics? Cultura e Scienza del Colore / Color, Culture, and Science, Vol. 4, pp. 22-30. Available at http://jcolore. gruppodelcolore.it/numeri/pdf/R0415_v04_11_2015_secured.pdf, last accessed on May 25, 2016.

Sandford, Jodi L. forthcoming. Cognitive Entrenchment of Color Category Associates and Implicit Attitudes in English. In: Mari Uusküla \& Geda Paulsen \& Jonathan Brindle (eds.) Colour Language and Colour Categorization. Newcastle upon Tyne: Cambridge Scholar Publishing. 
Schmid, Hans Jörg 2007. Entrenchment, Salience, and Basic Levels. In: Dirk Geeraerts \& Hubert Cuyckens (eds.) The Oxford Handbook of Cognitive Linguistics. Oxford: Oxford University Press, pp. 117-138. DOI:10.1093/ oxfordhb/9780199738632.013.0005.

Schmid, Hans Jörg 2013. Is Usage more than Usage After All? The Case of English not that. Linguistics, Vol. 51, No. 1, pp. 75-116. http://dx.doi.org/10.1515/ling2013-0003.

Schmid, Hans Jörg 2014. A Framework for Understanding Linguistic Entrenchment and Its Psychological Foundations in Memory and Automatization. In: Hans Jörg Schmid (ed.) Entrenchment, Memory and Automaticity: The Psychology of Linguistic Knowledge and Language Learning. Berlin: De Gruyter Mouton, pp. 1-24. Available at https://www.academia.edu/8953816/A_framework_for_ understanding_linguistic_entrenchment_and_its_psychological_foundations_ in_memory_and_automatization._Download_from_homepage_, last accessed on May 25, 2016.

Schmid, Hans Jörg 2015. A Blueprint of the Entrenchment-and-Conventionalization Model. Yearbook of the German Cognitive Linguistic Association, Vol. 3, No. 1, pp. 3-26. DOI: 10.1515/gcla-2015-0002.

Schmid, Hans Jörg \& Mantlik, Anette 2015. Entrenchment in Historical Corpora? Reconstructing Dead Authors' Minds from their Usage Profiles. Anglia, Vol. 133, No. 4, pp. 583-623. http://dx.doi.org/10.1515/ang-2015-0056.

Sutrop, Urmas 2000. The Basic Colour Terms of Estonian. Trames, Vol. 4, No. 2, pp. 143168.

Sutrop, Urmas 2001. List Task and Cognitive Salience Index. Field Methods, Vol. 13, No. 3, pp. 263-276. http://dx.doi.org/10.1177/1525822X0101300303.

Sutrop, Urmas 2002. The Vocabulary of Sense Perception in Estonian: Structure and History. Frankfurt am Main \& Berlin \& Bern \& Bruxelles \& New York \& Oxford \& Wien: Peter Lang.

Talmy, Leonard 2000. Toward a Cognitive Semantics. Volume II: Typology and Process in Concept Structuring. Cambridge, MA: MIT Press. Available at http:// linguistics.buffalo.edu/people/faculty/talmy/talmyweb/TCS.html, last accessed on May 25, 2016.

Talmy, Leonard 2005. Foreword. In: Monica Gonzalez-Marquez \& Irene Mittelberg \& Seana Coulson \& Michael J. Spivey (eds.) Methods in Cognitive Linguistics. Amsterdam \& Philadelphia: John Benjamins Publishing Company, pp. xi-xxi. DOI: 10.1075/hcp.18.

Uusküla, Mari \& Sutrop, Urmas 2007. Preliminary Study of Basic Colour Terms in Modern Hungarian. Linguistica Uralica, Vol. 43, No. 2, pp. 102-123. Available at http://www.eap.ee/public/Linguistica_Uralica/2007/issue_2/ling-2007-2-4.pdf, last accessed on May 25, 2016.

Uusküla, Mari 2007. The Basic Colour Terms of Finnish. SKY Journal of Linguistics, Vol. 20, pp. 367-397. Available at https://www.academia.edu/9109314/The_basic_ colour_terms_of_Finnish, last accessed on May 25, 2016.

Uusküla, Mari 2008. The Basic Colour Terms of Czech. Trames, Vol. 12, No. 1, pp. 3-28. DOI: $10.3176 /$ tr.2008.1.01. 